\title{
Rheology investigation of waste LDPE and crumb rubber modified bitumen
}

\author{
Hosein Zanjirani Farahani ${ }^{\mathrm{a}}$, Massoud Palassi ${ }^{\mathrm{a}^{*}}$ and Saeed Sadeghpour Galooyak $^{\mathrm{b}}$
}

${ }^{a}$ School of Civil Engineering, College of Engineering, University of Tehran, Enghelab Ave., Tehran, Iran

${ }^{b}$ Refining Technology Development Division, Research Institute of Petroleum Industry, Tehran, Iran

\begin{tabular}{l}
\hline A R T I C L EI N F O \\
\hline Article history: \\
Received 26 June, 2017 \\
Accepted 8 November 2017 \\
Available online \\
8 November 2017 \\
\hline Keywords: \\
Bitumen \\
Waste material \\
LDPE \\
Aging \\
BBR
\end{tabular}

\section{A B S T R A C T}

\begin{abstract}
In this article, waste plastics (low-density polyethylene, LDPE) and crumb rubber have been utilized to solve one of the most important environmental issues and to improve bitumen performance properties by these low cost materials. At first, modified bitumen samples were made using high shear mixer, then classic and performance tests were performed on them. It has been observed that adding low-density polyethylene and crumb rubber to the bitumen leads to improvement of classical characteristics. Then, after conducting dynamic shear rheometer test on modified bitumen samples, it was found that the sample containing 3\% LDPE and 3\% crumb rubber has the best performance. Conducting short-term and long-term aging experiments on samples containing 3\% LDPE showed improved performance at high temperature services. After BBR test, more appropriate performance grade is observed for the sample containing $3 \%$ LDPE $3 \%$ crumb rubber.
\end{abstract}

(C) 2018 by the authors; licensee Growing Science, Canada.

\section{Introduction}

Polymer modification of bitumen is the incorporation of polymers in bitumen by mechanical mixing or chemical reaction. The chemical behavior and reactivity of polymers, however, are also supposed to affect their compatibility with bitumen, which may have a direct effect on the result of modified bitumen characteristics (Al-Hadidy et al., 2011; Navarro et al., 2009; Martin et al., 2006; González et al., 2008). In the case of enhancing properties, the cost will increase. So allowing the degree of enhancing characteristics to be high enough to cover the additional cost will result in more cost effectiveness of modified bitumen. For reducing cost, some inexpensive polymeric materials, especially wastes and by-products e.g. waste rubber, waste plastics, could have potential applications with greater success in the future (Brovelia et al., 2015; Cuadri et al., 2013; Fuentes- Audén et al., 2008; Fang et al., 2012; González et al., 2016).

* Corresponding author. Tel: +98-21-61112273, Fax: +98-21-66403808

E-mail addresses: mpalas@ut.ac.ir (M. Palassi)

(C) 2018 by the authors; licensee Growing Science, Canada. doi: $10.5267 /$ j.esm.2017.11.002 
The various investigated polymers are plastomers (e.g. polyethylene (PE), polypropylene (PP), ethylene- vinyl acetate (EVA), ethylene-butyl acrylate (EBA)) and thermoplastic elastomers (Sengoz et al., 2009; Garcia et al., 2007; Naskar et al., 2012); but none of them were initially designed for bitumen modification. These polymers have been suggested for improving the properties of bitumen, such as higher stiffness at high temperatures, higher cracking resistance at low temperatures, better moisture resistance or longer fatigue life (Alatas et al., 2007; Gorkem \& Sengoz, 2009; Tayfur et al., 2013; Fang et al., 2013; Naskar et al., 2010, Aliha et al., 2015). These additives improved on one hand the characteristics of bitumen and on the other hand the mechanical performances of the asphalt mix (Moreno-Navarro et al., 2015; Brovellia et al., 2015; Navarro et al., 2007). Nevertheless, the cost of modified bitumen represents between $60 \%$ and $150 \%$ of pure bitumen price (Aguiar-Moya et al., 2013). Thus, the use of recycled materials can be a significant economical alternative (Fang et al., 2008; Li et al., 2013; Mazzoni et al., 2017; Fang et al., 2013). Hınıslığlu, \& A ğar (2004) reported that 4\% highdensity PE (HDPE), $165^{\circ} \mathrm{C}$ of mixing temperature and $30 \mathrm{~min}$ of mixing time were optimum conditions for Marshall stability. Kofteci et al. (2014) studied three types of waste plastics such as window, blinds and cable wastes based polyvinyl chloride. The results showed that the modification of bitumen with PVC window and blinds wastes in the amount of 1-3\% improved properties of bitumen at high temperatures. Despite the advantages of window waste and blinds waste additives at high temperatures, low temperatures properties of modified bitumen were not affected by these additives. Only $5 \%$ cable wastes improved properties of bitumen at low temperatures.

The goal of the present research is to study the effect of the waste LDPE and CR on the bitumen performance. For this purpose, blends of bitumen and several waste polymers were prepared, and further classical and rheological characterizations were carried out.

\section{Materials and Method}

\subsection{Materials}

The $85 / 100$ penetration grade bitumen with softening point of $45^{\circ} \mathrm{C}$, penetration of $90 \mathrm{dmm}$, more than $100 \mathrm{~cm}$ ductility, $0.75 \mathrm{~Pa}$.s viscosity, less than $1 \%$ weight loss in RTFO and with performance grade PG 64-16 obtained from Isfahan Refinery has been used to mix with waste materials. Crumb rubber was prepared from Qom Rubber Industries Company with the characteristics shown in Table 1.

Table 1. Characteristics of crumb rubber

\begin{tabular}{lc}
\hline \multicolumn{1}{c}{ Substance } & Weight (\%) \\
\hline Hydrocarbons (natural and synthetic rubber) & $\mathbf{5 3}$ \\
Carbon black & $\mathbf{3 2}$ \\
THF extractable $\left(\mathrm{C}_{4} \mathrm{H}_{8} \mathrm{O}\right)$ & $\mathbf{1 1}$ \\
Ash & $\mathbf{4}$ \\
\hline
\end{tabular}

Waste plastics (Fig. 1) with the properties given in Table 2 were supplied from Isfahan Municipality waste recycling factory.
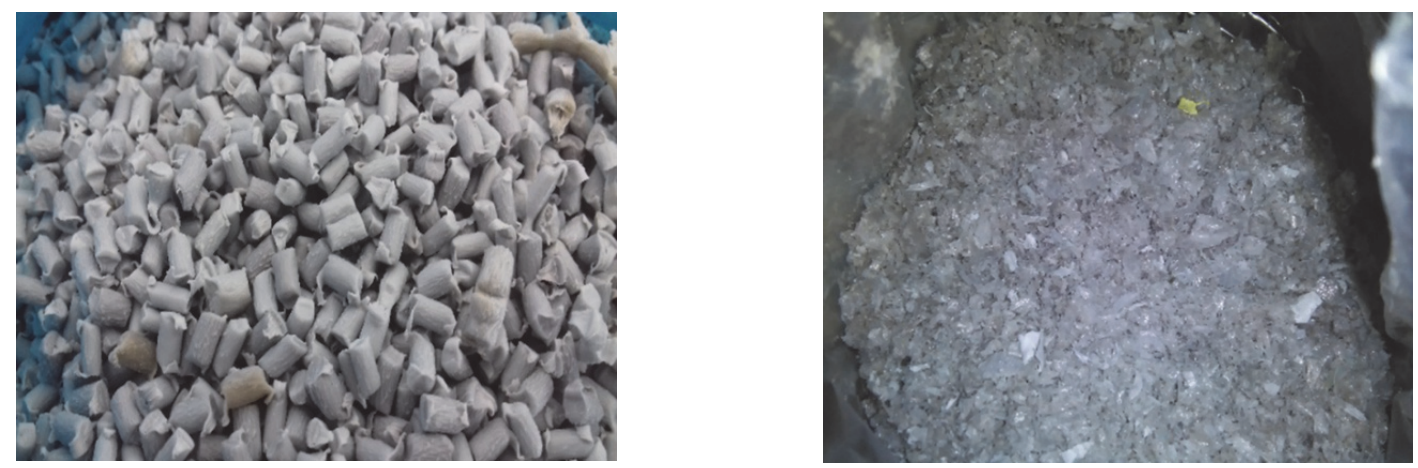

Fig. 1. Waste Plastic PE1 \& PE2 
Table 2. Specifications of recycled plastics

\begin{tabular}{lccc}
\hline \multicolumn{1}{c}{ Specifications } & Unit & Amount & Standard \\
\hline MFI $(1900 \mathrm{C} / 2.16 \mathrm{~kg})$ & $\mathrm{gr} / 10 \mathrm{~min}$ & 0.75 & ASTM D 1238 \\
Density & $\mathrm{gr} / \mathrm{ml}$ & 0.9210 & $\mathrm{TSTM} 209 \mathrm{~B}$ \\
Softening point & ${ }^{0} \mathrm{C}$ & 94 & ASTM D 1525 \\
Temperature thermal cracking & ${ }^{0} \mathrm{C}$ & 33 & ASTM D 648 \\
Elongation at break & $\%$ & $300 \mathrm{~min}$. & ASTM D 882 \\
Force elongation at break & $\mathrm{kg} / \mathrm{cm}^{2}$ & $170 \mathrm{~min}$. & ASTM D 882 \\
Paykan effect on sample & $\mathrm{gr}$ & $120 \mathrm{~min}$. & ASTM D 1709 \\
\hline
\end{tabular}

\subsection{Preparation of Modified Binders}

To study the impact of waste polymers and crumb rubber on bitumen, first it is necessary to study the compounds level, mixture situation and substances impressibility on bitumen. The percentages of each of the substances are chosen by considering the classical tests which are performed on each of waste plastics and crumb rubber.

where, PE1= Polyethylene (waste LDPE) type 1 as shown in Fig. 1 and PE2= Polyethylene (waste LDPE) type 2 as shown in Fig. 1. The contents of PE1, PE2 and crumb rubber in prepared samples have been specified in Table 3 and Table 4.

Table 3. List of samples prepared with different percentage of PE1 and crumb rubber

\begin{tabular}{ccc}
\hline Sample & PE1 (\%) & CR (\%) \\
\hline A1 & $\mathbf{3}$ & $\mathbf{1}$ \\
A2 & $\mathbf{3}$ & $\mathbf{3}$ \\
A3 & $\mathbf{3}$ & $\mathbf{5}$ \\
A4 & $\mathbf{5}$ & $\mathbf{1}$ \\
A5 & $\mathbf{5}$ & $\mathbf{3}$ \\
A6 & $\mathbf{5}$ & $\mathbf{5}$ \\
A7 & $\mathbf{7}$ & $\mathbf{1}$ \\
A8 & $\mathbf{7}$ & $\mathbf{3}$ \\
A9 & $\mathbf{7}$ & $\mathbf{5}$ \\
\hline
\end{tabular}

Table 4. List of samples prepared with different percentage of PE2 and crumb rubber

\begin{tabular}{ccc}
\hline Sample & PE2 (\%) & CR (\%) \\
\hline B1 & $\mathbf{3}$ & $\mathbf{1}$ \\
B2 & $\mathbf{3}$ & $\mathbf{3}$ \\
B3 & $\mathbf{3}$ & $\mathbf{5}$ \\
B4 & $\mathbf{5}$ & $\mathbf{1}$ \\
B5 & $\mathbf{5}$ & $\mathbf{3}$ \\
B6 & $\mathbf{5}$ & $\mathbf{5}$ \\
B7 & $\mathbf{7}$ & $\mathbf{1}$ \\
B8 & $\mathbf{7}$ & $\mathbf{3}$ \\
B9 & $\mathbf{7}$ & $\mathbf{5}$ \\
\hline
\end{tabular}

\subsection{Experimental program}

After preparation of samples using a high shear mixer, classical and rheological tests were performed on the samples. In conventional tests, softening point (according to ASTM D36 standard test method) and needle penetration (according to ASTM D5 standard test method) were conducted on the prepared sample. Then, fresh binders were characterized by dynamic shear rheometer (DSR). DSR is the important test for the simulation of bitumen in high temperature services and could estimate temperature susceptibility of bitumen in asphalt paving. Furthermore, modified samples were aged in a rolling thin film oven (RTFO), and then aged binders in RTFO were aged again using a pressure aging vessel (PAV). The PAV simulate the long term aging of bitumen in life service. After PAV, rheological properties of samples were examined by a dynamic shear rheometer to investigate the rheological characteristics of modified samples. Finally, stiffness of samples at low temperature service was tested using a bending beam rheometer (BBR). In all of the procedures, to increase the precision, samples were selected randomly for testing and all of the tests were repeated at least two times.

\subsection{Testing method}

Softening point according to ASTM D36 standard test method and needle penetration at $25{ }^{\circ} \mathrm{C}$ according to ASTM D5 standard test method were conducted on the prepared samples. Viscoelastic properties were determined by using dynamics shear rheometer (DSR) equipped with parallel plates at frequency of $10 \mathrm{rad} / \mathrm{s}$ and temperatures from $30{ }^{\circ} \mathrm{C}$ to $80{ }^{\circ} \mathrm{C}$ according to ASTM D7175. In this study RTFO (ASTM D2872) and PAV (ASTM D6521) were used to age bitumen samples. Standardized 
conditions, i.e. $163{ }^{\circ} \mathrm{C}$ and $5 \mathrm{~h}$ for RTFO, $100{ }^{\circ} \mathrm{C}$ and $20 \mathrm{~h}$ for PAV, were used. The aged samples were evaluated by measuring their rheological properties. Finally, BBR (ASTM D6648) was performed on the samples. The BBR device measures beam deflection under a constant load at low temperatures. During testing, the bitumen beams (125 mm long, $12.5 \mathrm{~mm}$ wide and $6.25 \mathrm{~mm}$ thick) were submerged in a constant temperature bath and keep at test temperature for $60 \mathrm{~min}$. A constant weight of $100 \mathrm{gr}$. was then applied to the bitumen beam, which was supported at both ends, and the deflection of center point was measured. Depending on the value of this deflection, creep stiffness and creep rate were measured at several loading times.

\section{Analysis of Results}

\subsection{Physical Properties}

Penetration test is carried out according to ASTM-D5 standard for all bituminous samples. This test is one of the physical tests to determine stiffness of bitumen under specific load conditions. According to Fig. 2, it can be observed that by increasing polymer percent, bitumen penetration is decreased. Decreasing penetration degree means fluidity is decreased and the consistency of bitumen at high temperatures is increased. Samples A1 to A6 have better penetration degree for using in road construction. By increasing LDPE contents in samples A7 to A9, penetration level is decreased continually. Similar results are observed for samples including LDPE Type 2 (Fig. 2).

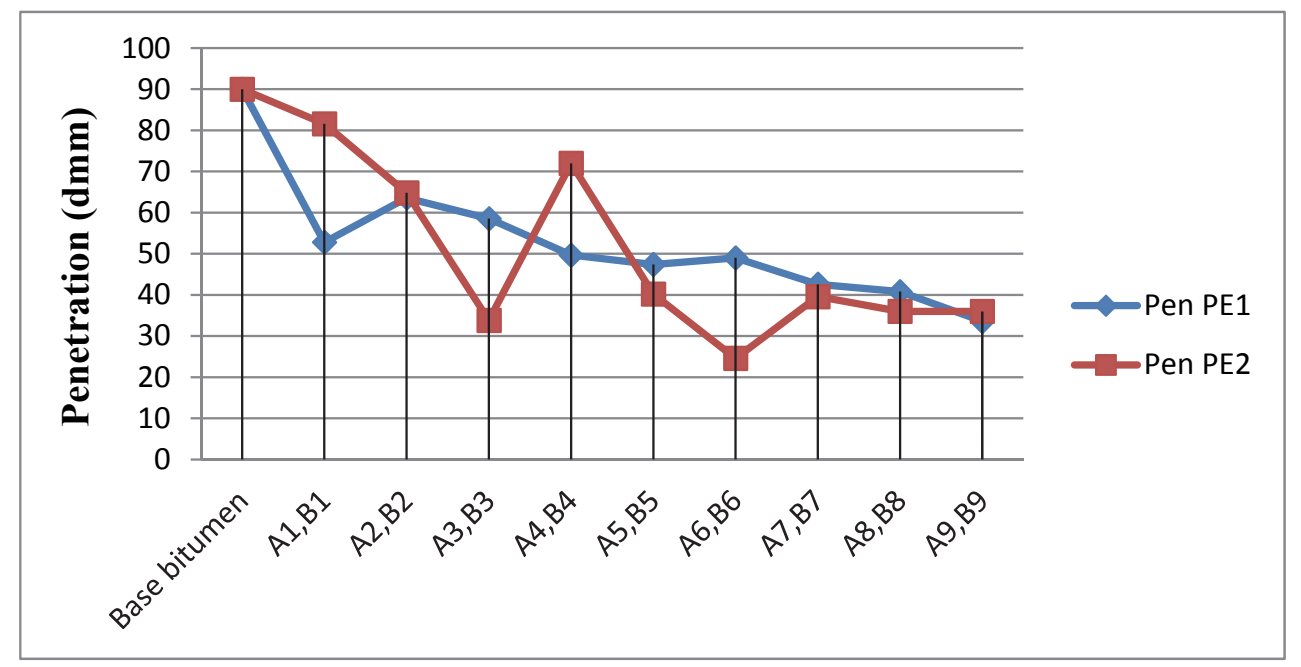

Fig. 2. Penetration result for PE1 and PE2

Softening point for base and modified bitumen is measured according to ASTM-D 36 standard test method. Higher softening point causes less thermal sensitivity. As it can be observed in Fig. 3, by adding PE and crumb rubber to bitumen, softening point would be increased.

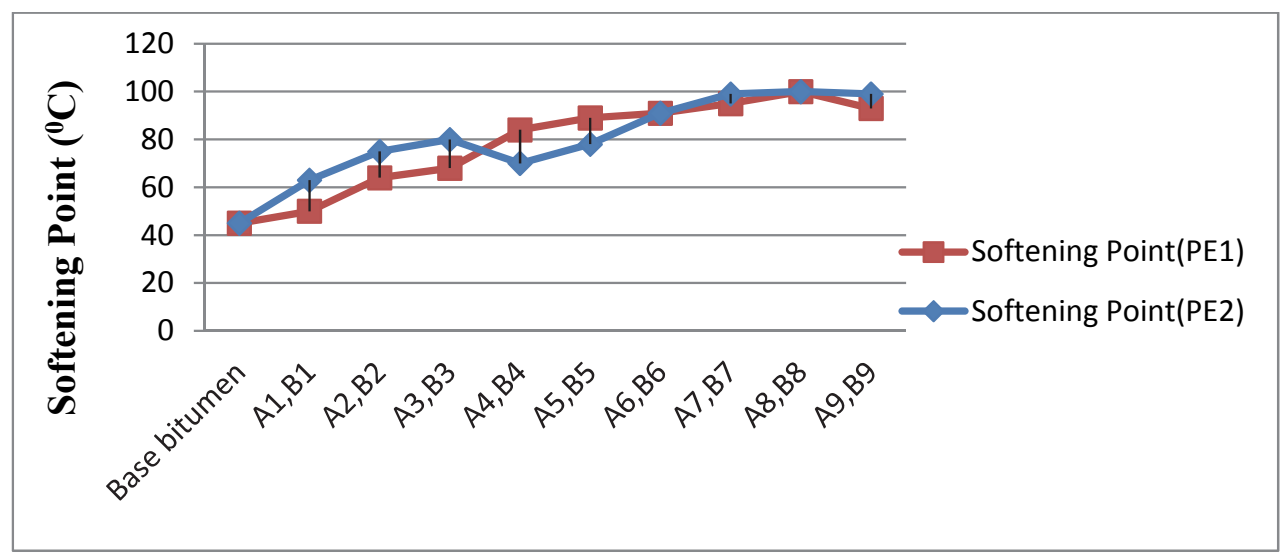

Fig. 3. Softening point result for PE1 and PE2 


\subsection{Performance experiments of bitumen}

Since the performance of bitumen is related to loading time and temperature, the best test to evaluate bitumen behavior is dynamic shear rheometer test; therefore, this test is performed on all samples. This test measures bitumen rheology properties in middle to high temperatures (complex shear modulus and phase angle). In DSR apparatus, bitumen is placed as a disk between two parallel plates which one of them is fixed and another one oscillates. Mobile plate moves from point A to B and then returns to point $\mathrm{A}$ and from there moves to point $\mathrm{C}$ and returns to point $\mathrm{A}$ (Fig. 4). This oscillation is computed as a cycle and DSR repeats this process regularly. The oscillation frequency would be equal to10 rad/s $(1.59 \mathrm{~Hz}$ cycle per second).

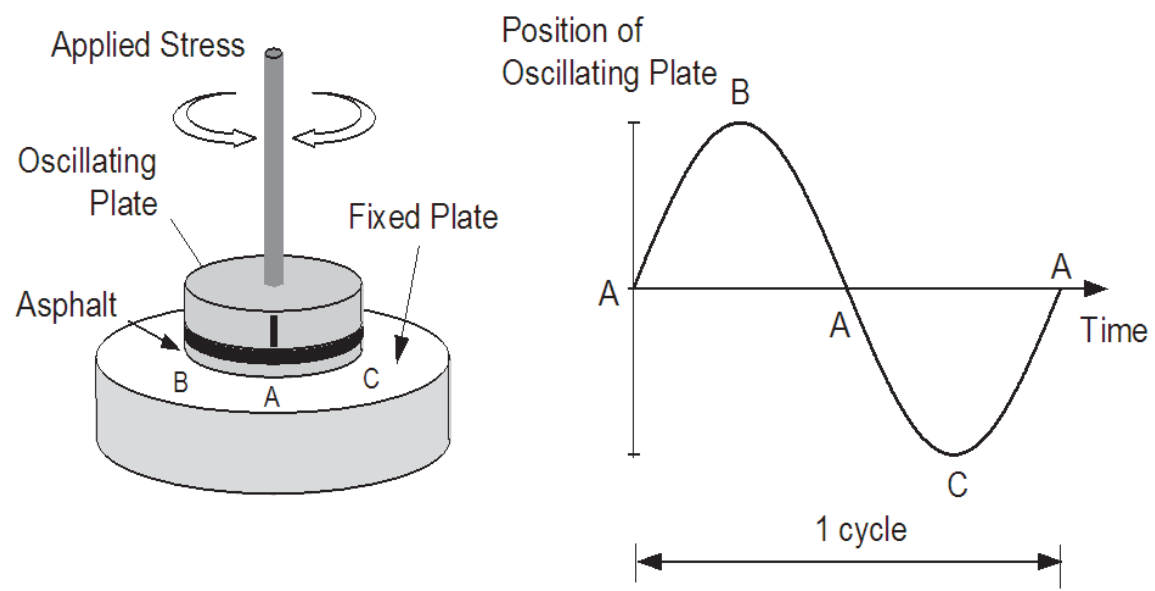

Fig. 4. Dynamic shear rheometer (Ghile, 2006)

DSR apparatus identify bitumen's mid and high temperature rheological behavior by measuring complex shear modulus $\left(\mathrm{G}^{*}\right)$ and phase angle $(\delta) . \mathrm{G}^{*}$ is an index of resistance of a substance toward deformation under repeated pulses in shear tension. It includes two parts: elastic modulus (recoverable) and viscous modulus (irrecoverable). In this research, DSR is performed in the range of $30-85^{\circ} \mathrm{C}$. To compare samples performance, $3 \mathrm{wt} . \%$ of crumb rubber and different percentages of PE1 and PE2 were blended and results were compared. It can be observed that in all results, polymer Type 1 is mixed better with bitumen because of its regular dimension and equal size and is distributed better in bitumen, therefore it shows better results; however, these differences are not considerable.

Rheological curves are designed for $1 \%, 3 \%, 5 \%$ crumb percentage. By comparing these graphs, it can be observed that samples with $3 \%$ crumb rubber have better performance; since samples containing $1 \%$ crumb rubber cannot improve performance of bitumen at low service temperatures. Moreover, bitumen which has $5 \%$ crumb rubber is not recommended for regions with cold climate conditions, because it returns high levels of performance (more than $82^{\circ} \mathrm{C}$ ) and is suitable only for very hot climates. So, the samples containing 3\% crumb rubber are discussed in this paper.

As it can be observed in Fig. 5, complex modulus results are provided for samples which contain polymers type 1 and 2 with $3 \%$ crumb rubber. All samples have larger complex modulus in comparison to base bitumen. By increasing polymer percentage, this parameter is increased since waste polyethylene and crumb rubber establish more adhesiveness in combination to bitumen which causes increase in hardness and viscosity of bitumen. Therefore, complex modulus and high performance grade is increased. 


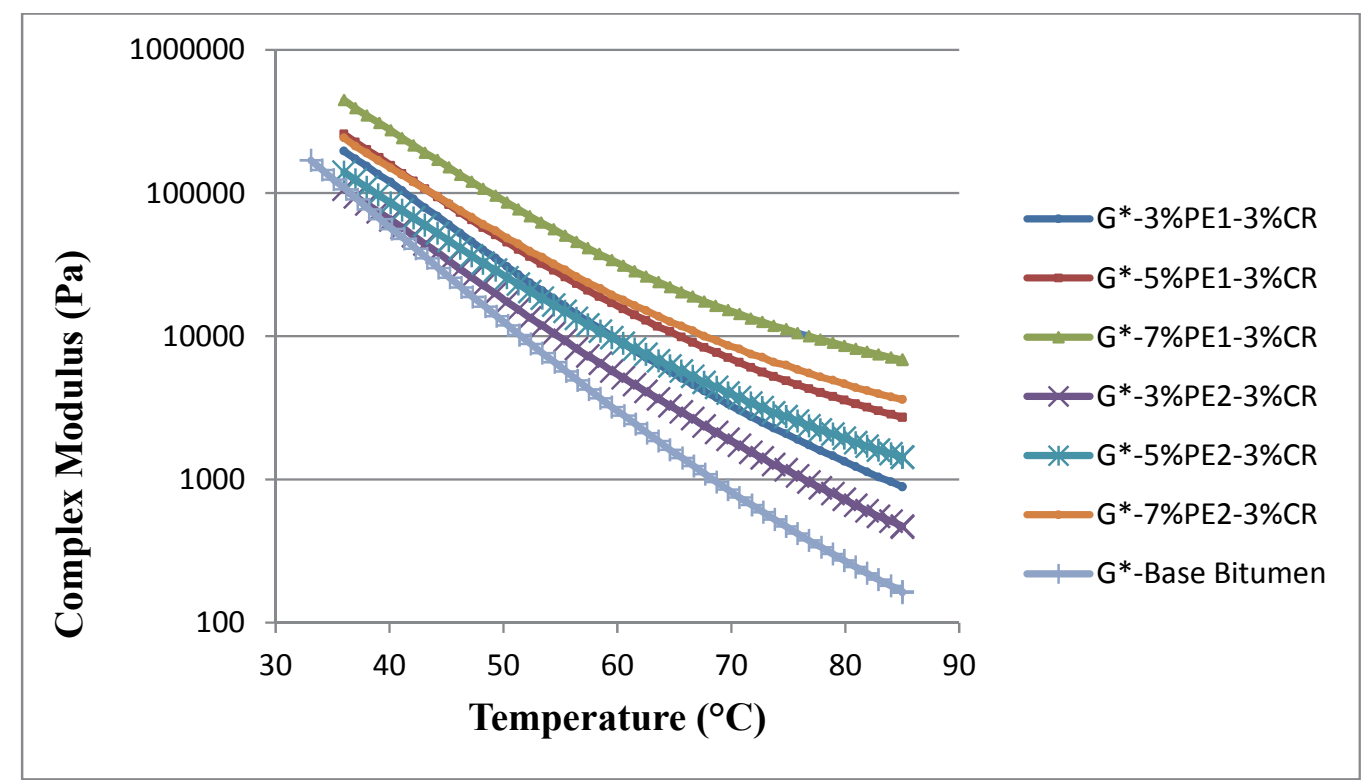

Fig. 5 The complex modulus of base and modified bitumen samples with different percentages of PE1, PE2 and 3\% crumb Rubber

Finally, phase angle graph and other parameters have been studied. As it can be observed in Fig. 6, by adding waste polyethylene and crumb rubber to bitumen, this parameter is decreased for all samples in comparison to base bitumen. Decreasing $\delta$ level means decreasing the Loss Modulus (GarcíaMorales et al., 2007); therefore, high temperature performance of modified bitumen is improved.

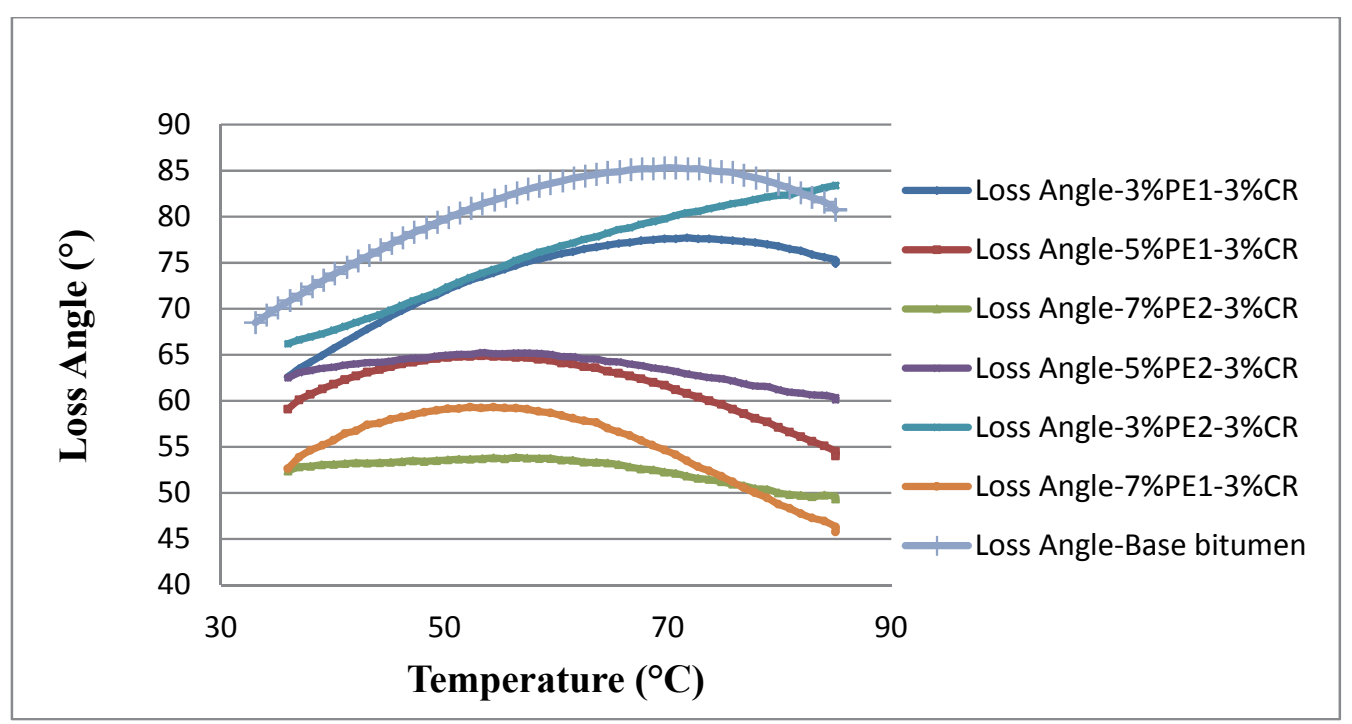

Fig. 6 The Phase Angle of base and modified bitumen samples with different percentages of PE1, PE2 and 3\% Crumb Rubber

Permanent deformation i.e., rutting is related to $\mathrm{G}^{*} / \sin \delta$ parameter. This item (rutting) is obtained by binder viscous behavior in relation to traffic load in high temperatures. Therefore, $\mathrm{G}^{*} / \mathrm{Sin} \delta$ level which is called rutting factor should be more than $1 \mathrm{kPa}$ in test temperature for unaged binder. This minimum level of $\mathrm{G}^{*} / \sin \delta$ indicates that binder has necessary hardness to apply in asphalt mixture and because of binder characteristics, the level of rutting in asphalt is in minimum level. As much as the level of $\mathrm{G}^{*}$ is high and $\delta$ level is low, the binder resistance against rutting would be more (Ameri et al. 2016). As it can be observed in Fig. 7, adding waste polyethylene and crumb rubber to bitumen improves modified bitumen rutting parameters. Among the samples, the sample with 7\% PE, has higher $\mathrm{G}^{*} / \sin \delta$ in all temperature ranges. Since samples consisting of $7 \%$ and $5 \%$ waste polyethylene reach 1 
$\mathrm{kPa}$ in higher temperatures than $82^{\circ} \mathrm{C}$ which is higher limit of performance grade, the mixture comprising $3 \%$ polymer and $3 \%$ crumb rubber is chosen as optimum mixture.

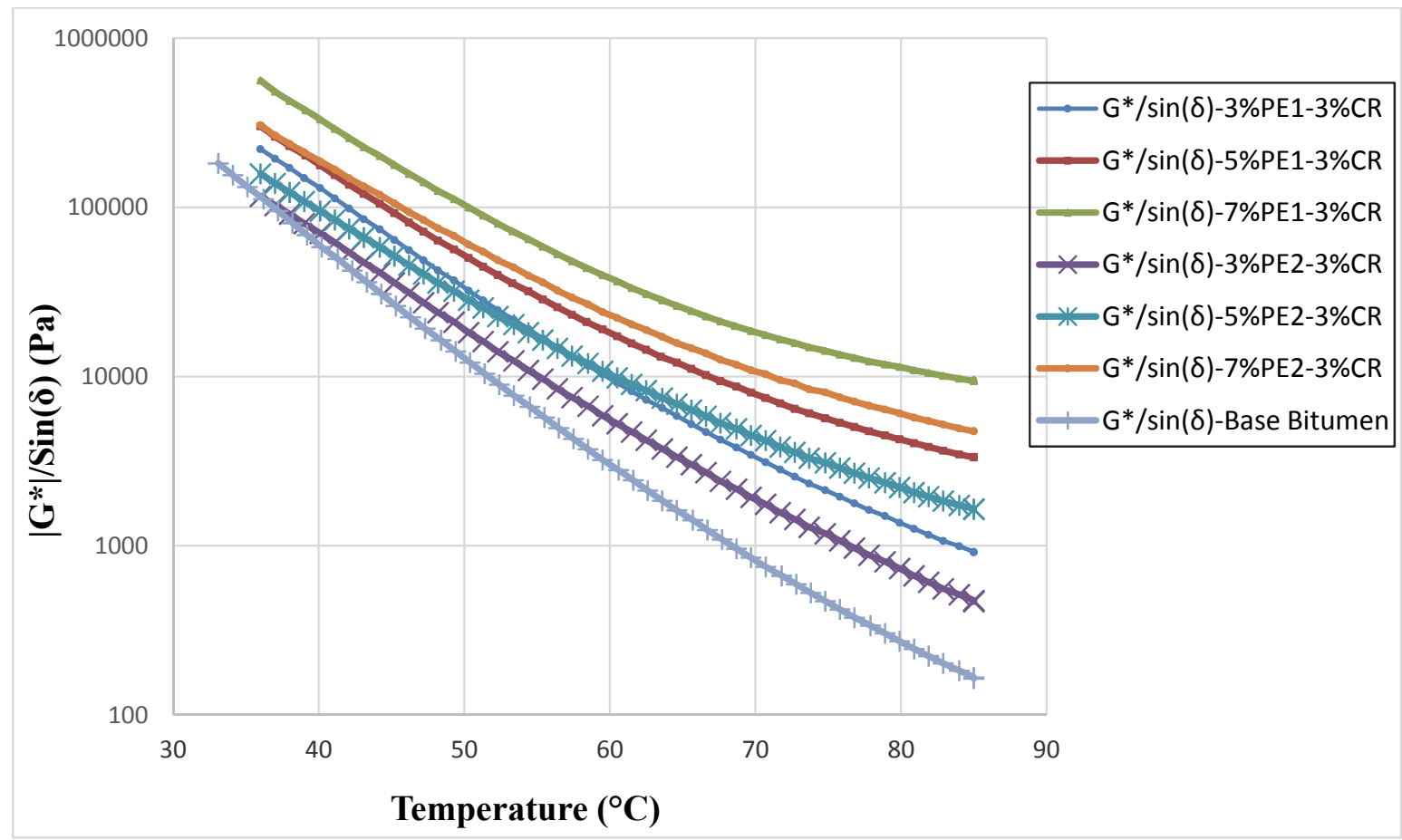

Fig. 7. Rutting factor for base and modified bitumen samples with different percentages of PE1, PE2 and $3 \%$ crumb Rubber

According to SHRP standard, the temperature that rutting factor $\left(\mathrm{G}^{*} / \sin \delta\right)$ reaches $1 \mathrm{kPa}$ is selected as a high temperature of performance grade. In Table 5 the result of $\mathrm{G}^{*} / \sin \delta$ curves is presented as SHRP temperature. It is observed that high temperature of bitumen has remarkably increased with increasing polymer percent.

\subsection{Low Temperature Experiments of Bitumen}

\subsubsection{Aging Experiments}

Since the SHRP tests simulate bitumen behavior throughout service life, the bitumen samples are affected by short-term and long-term aging experiments. Basically, the bitumen binders are aged under two mechanisms including evaporation of oil and lightweight materials in bitumen and oxidation by reacting with oxygen. These two mechanisms take place throughout mixing process and road construction which are associated with high temperature and airflow. The RTFO test is used to simulate the short-term aging test. After constructing road, although the aging process continues, the oxidation mechanism is dominant, which is due to relatively moderate ambient temperatures in this phase. Based on SHRP specifications, the aging through the service life is simulated by the PAV test. It should be noted that the binder samples which are aged in the PAV machine, must be aged during the RTFO test previously. Therefore, the product of PAV represents the binder which is exposed to all environmental conditions during production (mixing operation and road construction) and then, at the time of the service. Based on ASTM D2872 method, the RTFO test is carried out to achieve two purposes. The first aim is to produce the aging binder which will be used for next physical tests and the second one is to determine the amount of volatile materials which is reduced from the bitumen during the process. Weight loss shows aging that can be occurred in the binder during mixing operation and road construction. Formation of products by oxidation causes that some of the binders gain weight even in the RTFO test. In this test, the thin film of the binder is regularly exposed to heat and airflow. 
In Fig. 8 the temperature in which $\mathrm{G}^{*} / \mathrm{Sin} \delta$ parameter is equal to $1 \mathrm{kPa}$ is reported for no aging bitumen samples. As it can be seen in Fig. 8, all samples compared to base bitumen, rises to $1 \mathrm{kPa}$ at higher temperature and this implies better performance of these. It is clear that second type of the plastic makes bitumen to be less stiff and the samples including $\mathrm{A} 4$ to $\mathrm{A} 9$ will be $1 \mathrm{kPa}$ at the temperatures above $82{ }^{\circ} \mathrm{C}$. However, this temperature $\left(82{ }^{\circ} \mathrm{C}\right)$ is reported based on the maximum high temperature of SHRP performance grade.

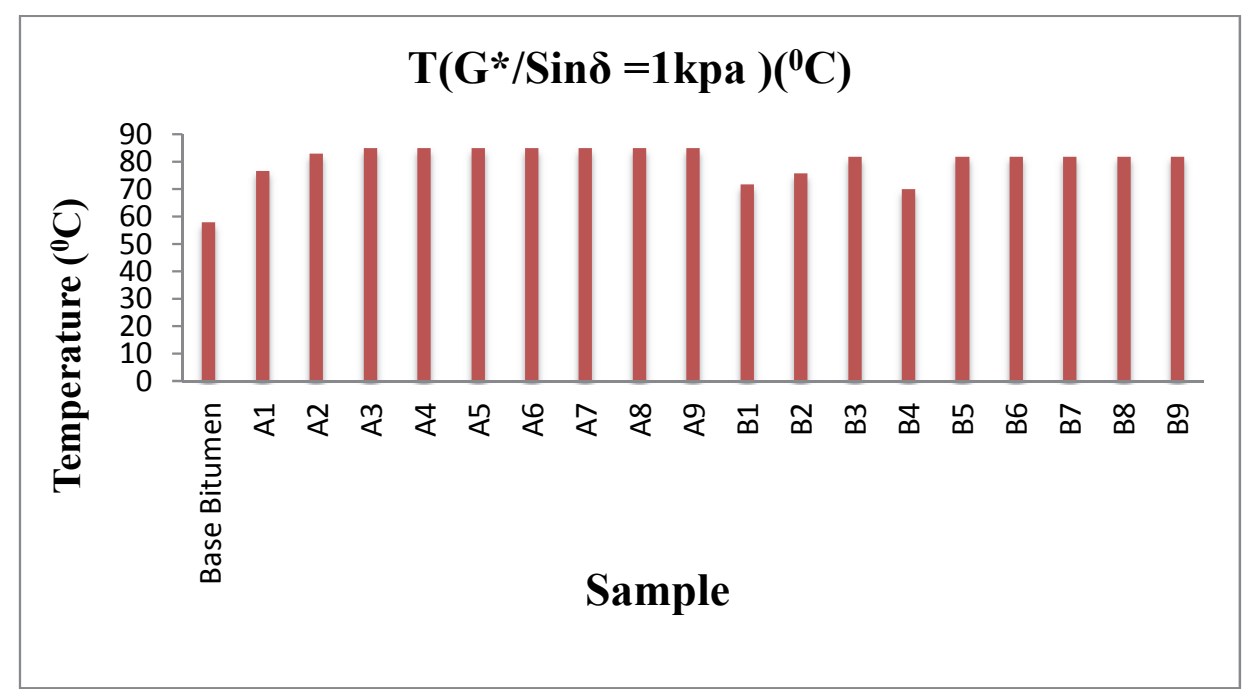

Fig. 8 DSR test results of base and modified bitumen before short term ageing

In Fig. 9, after conducting the short-term aging test on the samples, the maximum temperature in which $\mathrm{G}^{*} / \mathrm{Sin} \delta$ parameter is more than $2.2 \mathrm{kPa}$ is reported for the aging bitumen samples. The test temperature is almost constant for most samples.

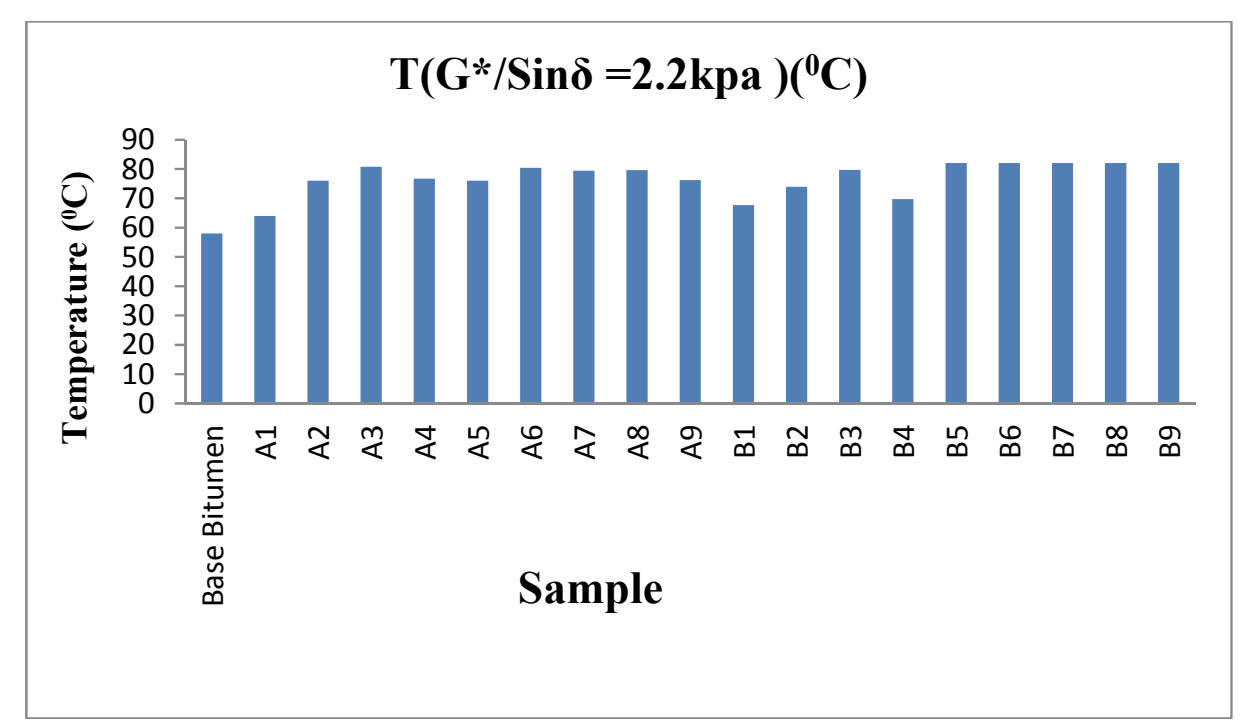

Fig. 9. DSR test results of base and modified bitumen after short term ageing

PAV test is performed according to ASTM-D6521 standard method. For simulating this type of aging, PAV machine is used in which binder exposes to high pressure and temperature for 20 hours. Since bitumen that is exposed to the long-term aging test has before been under operation and road construction processes, aged binders in RTFO is used in PAV test. PAV machine includes a pressure oven. Air pressure is supplied by one cylinder of clean and dry air equipped with a pressure regulator. In this test, the pressure is kept at $2070 \mathrm{kPa}$ and the temperature can be 90,100 or $110^{\circ} \mathrm{C}$. 
After PAV test, $G^{*}$. Sin $\delta$ parameter which is fatigue cracking criteria in mid temperature for all samples should be lower than $5000 \mathrm{kPa}$. In Fig. 10 the temperature in which $\mathrm{G}^{*}$. Sin $\delta$ is equal to 5000 $\mathrm{kPa}$ is reported for all samples. As it can be seen in Fig. 11, A1, A2, A3, B1, B2 and B3 samples compared to base bitumen, rises to $5000 \mathrm{kPa}$ at lower temperature and this implies better performance of these samples against the fatigue cracking. It is obvious that second type of the plastic makes bitumen to be less stiff and has better performance. For the other samples $\mathrm{G}^{*}$. Sin $\delta$ is equal to $5000 \mathrm{kPa}$ at higher temperature and this implies poor performance of these samples against the fatigue cracking compared to the base bitumen.

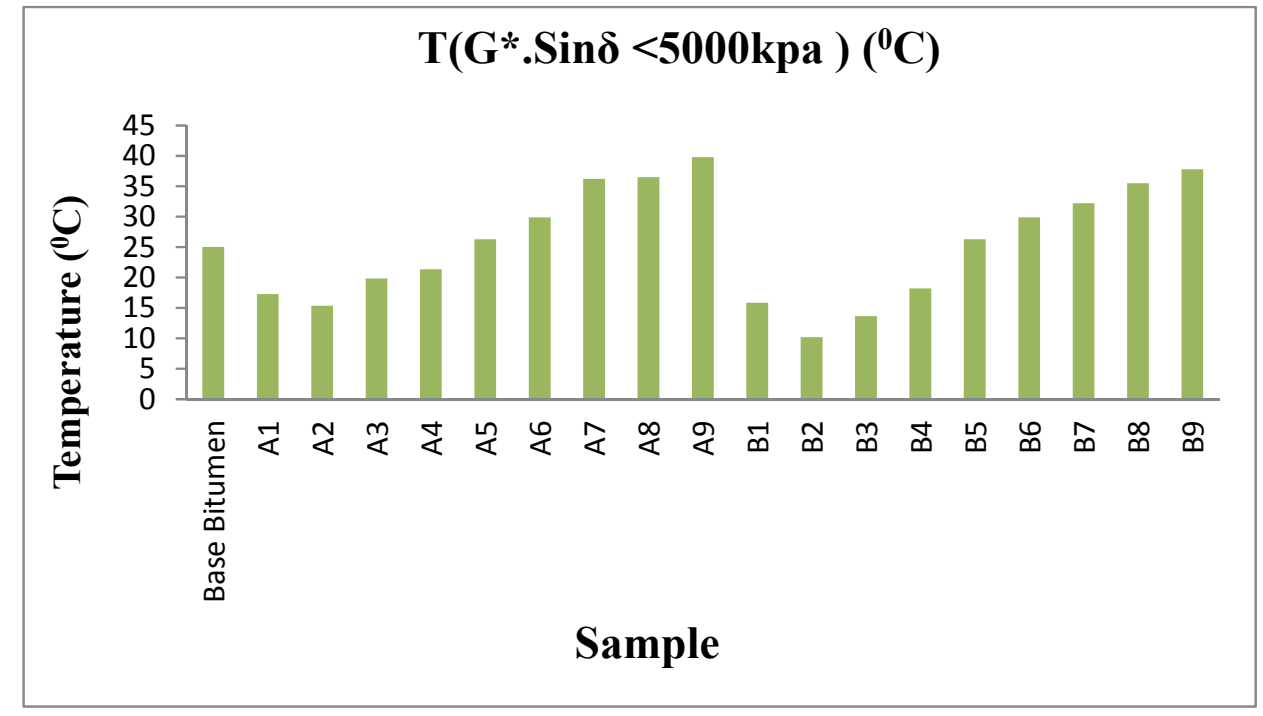

Fig. 10. DSR test results of base and modified bitumen after long term ageing

\subsubsection{Bending Beam Rheometer Test}

Since the bitumen binders are stiffer at low temperatures, their properties cannot be measured using DSR. Therefore, SHRP researchers used BBR machine to measure characteristics of binder at low temperatures. BBR measures deviation or creep rate of binder under a constant load and temperature according to ASTM 6648 standard test method. The temperatures of BBR test are related to the minimum temperature of load service. In these temperatures, binder acts like an elastic solid. In addition, BBR test is performed on the binders which are aged in the RTFO and PAV. Therefore, the test measures the performance of the binders after aging through mix operation and service life.

In BBR test, the creep stiffness (S) and creep rate $(\mathrm{m})$ can be evaluated by applying a constant load on the bitumen beam and measuring the central deviation rate of the beam during the test. The creep stiffness is the binder resistance against creep loading and $\mathrm{m}$-value is the rate of bitumen stiffness changes through loading.

In Fig. 11, the values of creep stiffness at $-6{ }^{\circ} \mathrm{C}$ are presented for both types of polymers. As it can be seen in Fig. 11, creep stiffness is decreased for the samples A1, A2, A3, B1, B2 and B3 compared to the base bitumen, which shows the improved performance of these samples compared to the base bitumen at low temperatures. It means that the modified bitumen has appropriate elasticity at low temperatures. However, the creep stiffness is increased for the other samples compared to the base bitumen, which means that the low temperature performance of these samples is deteriorated compared to the base bitumen. Moreover, since the values of creep stiffness for all samples are less than $300 \mathrm{MPa}$, the direct tensile test (DTT) is not necessary. 


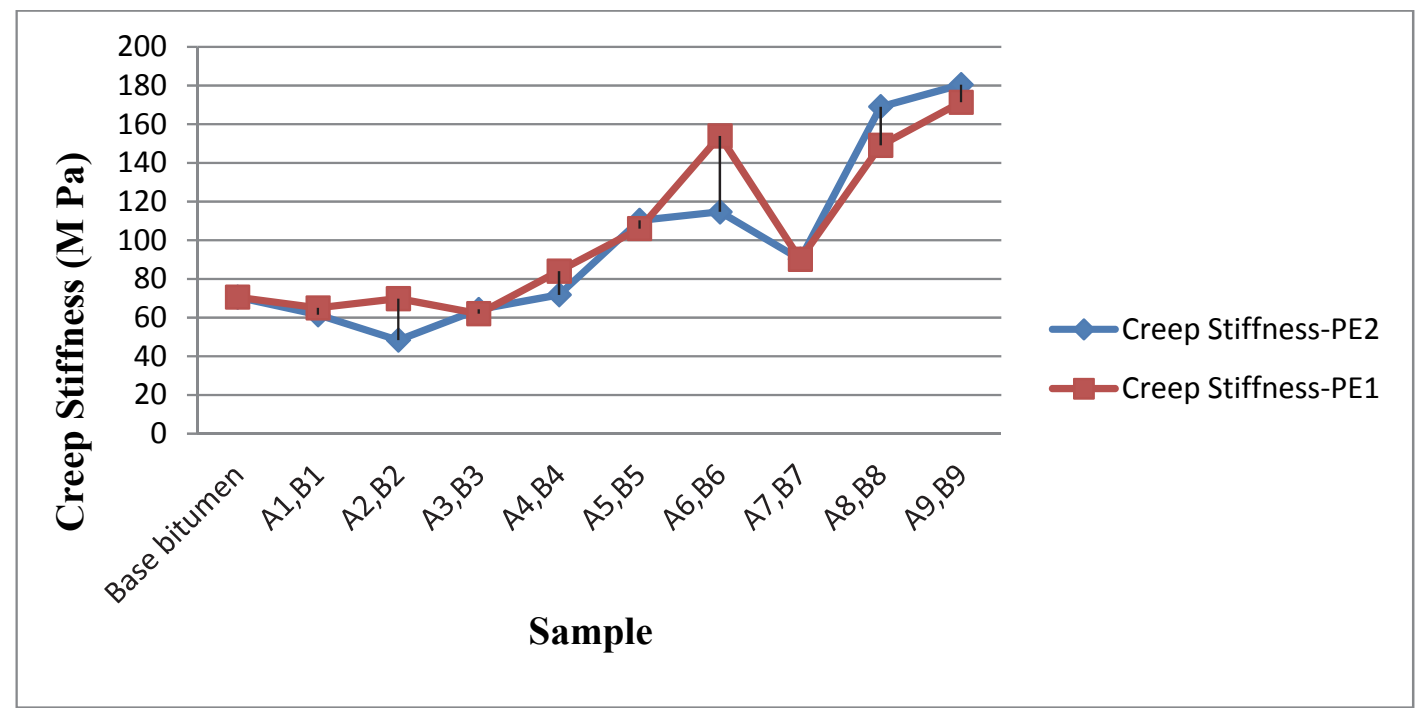

Fig. 11. Creep stiffness values of the Base and modified bitumen at $(-6){ }^{0} \mathrm{C}$

Fig. 12 shows the m-value for both types of polymers at $-6{ }^{0} \mathrm{C}$. As it is clear, rate of the creep stiffness changes is increased compared to the base bitumen, which leads to better resistance against cracking at low temperature. It can be due to poly-butadiene chains in rubber network, therefore flexibility of modified bitumen is increased it the low temperature with higher rate. However, for the other samples, creep rate is slightly decreased, which can be resulted from domination of polymer phase and bitumen stiffness. In fact, it leads to reverse effect on the low temperature of these samples compared to the base bitumen.

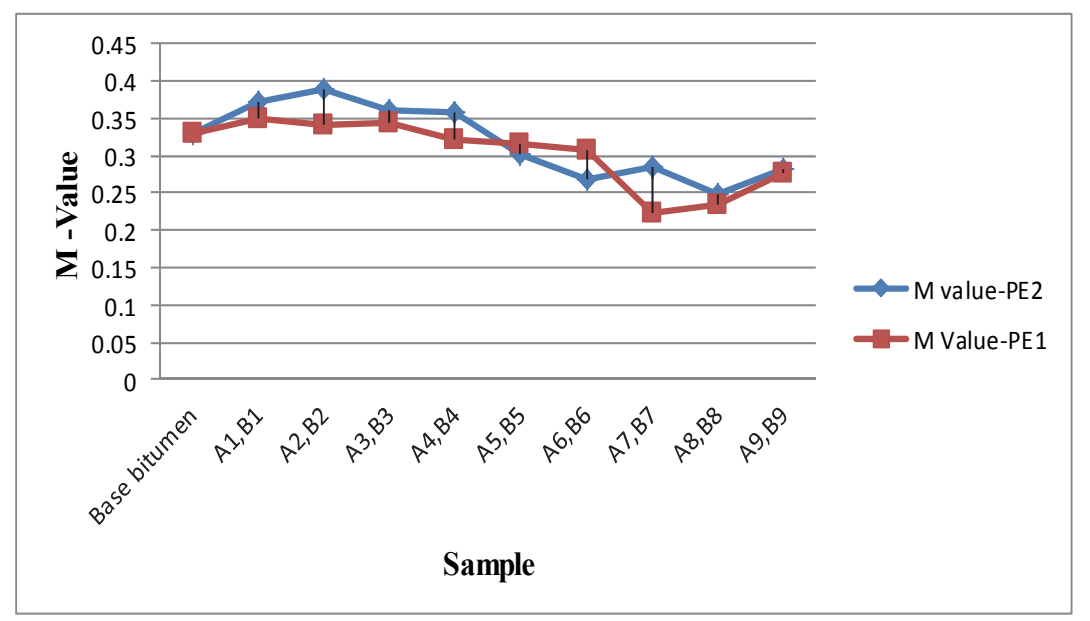

Fig. 12. $\mathrm{m}$-values of the Base and modified bitumen at $-6{ }^{\circ} \mathrm{C}$

According to SHRP method, the values of creep stiffness which are less than $300 \mathrm{MPa}$ and corresponding m-value of more than 0.3 show that tolerance of bitumen is $10^{\circ} \mathrm{C}$ less than the test temperature. The results of low temperature of BBR test as well as the results of high temperature of performance grade are shown in Table 5. In addition, performance grade (PG) is reported for all samples. It is observed that adding plastics and crumb rubber causes increase in the high temperature grade of modified samples compared to the base bitumen, which are recommended for tropical areas. However, for the samples A1, A2, A3, B1, B2 and B3, in addition to increase in the high temperature grade of bitumen, the low temperature grade is also increased. It shows that using waste materials leads to improvement in performance of bitumen in the high and low temperature services. Also, it implies on production of polymer modified bitumen for wide range of temperatures. Finally, the samples containing $\% 3$ plastic and $\% 3$ crumb rubber were introduced as the optimal mix. That is because they show better improvement in bitumen at the low and high temperatures. 
Table 5. The effect of modification on high and low temperatures performance grade (PG) of bitumen

\begin{tabular}{|c|c|c|c|c|c|}
\hline & & & High Temperature & Low Temperature $\left({ }^{\circ} \mathrm{C}\right)$ & \\
\hline Base Bitumen & $\mathbf{0}$ & $\mathbf{0}$ & 58 & -16 & PG 58-16 \\
\hline A1 & 3 & 1 & 64 & -22 & PG 64-22 \\
\hline A2 & 3 & 3 & 76 & -22 & PG 76-22 \\
\hline A3 & 3 & 5 & 82 & -16 & PG 82-22 \\
\hline A4 & 5 & 1 & 82 & -10 & PG 82-10 \\
\hline A5 & 5 & 3 & 76 & -16 & PG 76-16 \\
\hline A6 & 5 & 5 & 82 & -16 & PG 82-16 \\
\hline A7 & 7 & 1 & 82 & -10 & PG 82-10 \\
\hline A8 & 7 & 3 & 82 & -10 & PG 82-10 \\
\hline A9 & 7 & 5 & 82 & -16 & PG 82-10 \\
\hline$B 1$ & 3 & 1 & 70 & -22 & $P G 70-22$ \\
\hline$B 2$ & 3 & 3 & 76 & -22 & $P G$ 76-22 \\
\hline$B 3$ & 3 & 5 & 82 & -16 & $P G$ 82-16 \\
\hline B4 & 5 & 1 & 82 & -16 & $P G$ 82-16 \\
\hline$B 5$ & 5 & 3 & 82 & -16 & $P G$ 82-16 \\
\hline B6 & 5 & 5 & 82 & -10 & $P G 82-10$ \\
\hline B7 & 7 & 1 & 82 & -10 & $P G 82-10$ \\
\hline$B 8$ & 7 & 3 & 82 & -10 & $P G 82-10$ \\
\hline B9 & 7 & 5 & 82 & -10 & PG 82-10 \\
\hline
\end{tabular}

\section{Conclusions}

Because of severe temperature changes in some regions, researchers are interested to produce modified bitumen which can perform appropriately in the low, middle and high temperatures. Therefore, in order to produce low cost polymer modified bitumen, waste low density polyethylene accompanying crumb rubber were used in this research. According to the results, adding these waste materials to bitumen increases softening point and lowers the bitumen penetration. The samples including waste polyethylene and crumb rubber have more complex modulus and less phase angle in comparison to base bitumen at similar temperature and loading frequencies. From rheological investigation, it was observed that high temperature performance of bitumen was improved after adding waste polymers, but the samples including 5\% and 7\% LDPE are suggested for very hot climates, because they pass high range of performance grade specifications $\left(+82^{\circ} \mathrm{C}\right)$. Moreover, after performing the rheological investigation at low temperature using a bending beam rheometer, the low temperature limit of performance grade was improved for the samples containing 3\% LDPE and 3\% crumb rubber. As a result, the blend which includes 3\% LDPE and 3\% crumb rubber improves the high temperature and low temperature performance of bitumen simultaneously, and is considered as optimized blend.

\section{References}

Aguiar-Moya, J. P., Villegas-Villegas, R. E., Loría-Salazar, L. G., \& Salazar-Delgado, J. (2013). Use of Waste Products as Bitumen Modifiers in Costa Rica.

Alataş, T., \& Yilmaz, M. (2013). Effects of different polymers on mechanical properties of bituminous binders and hot mixtures. Construction and Building Materials, 42, 161-167.

Al-Hadidy, A. I., Yi-Qiu, T., \& Hameed, A. T. (2011). Starch as a modifier for asphalt paving materials. Construction and Building Materials, 25(1), 14-20.

Aliha, M. R. M., Fazaeli, H., Aghajani, S., \& Nejad, F. M. (2015). Effect of temperature and air void on mixed mode fracture toughness of modified asphalt mixtures. Construction and Building Materials, 95, 545-555.

Ameri, M., Nowbakht, S., Molayem, M., \& Aliha, M. R. M. (2016). Investigation of fatigue and fracture properties of asphalt mixtures modified with carbon nanotubes. Fatigue \& fracture of engineering materials \& structures, 39(7), 896-906.

Brovelli, C., Crispino, M., Pais, J., \& Pereira, P. (2015). Using polymers to improve the rutting resistance of asphalt concrete. Construction and Building Materials, 77, 117-123.

Cuadri, A. A., García-Morales, M., Navarro, F. J., \& Partal, P. (2013). Isocyanate-functionalized castor oil as a novel bitumen modifier. Chemical Engineering Science, 97, 320-327. 
González, E., Costa, L. M., Silva, H. M., \& Hilliou, L. (2016). Rheological characterization of EVA and HDPE polymer modified bitumens under large deformation at $20^{\circ}$ C. Construction and Building Materials, 112, 756-764.

Hınıslığlu, S., \& Ağar, E. (2004). Use of waste high density polyethylene as bitumen modifier in asphalt concrete mix. Materials Letters, 58(3), 267-271.

Fuentes-Audén, C., Sandoval, J. A., Jerez, A., Navarro, F. J., Martínez-Boza, F. J., Partal, P., \& Gallegos, C. (2008). Evaluation of thermal and mechanical properties of recycled polyethylene modified bitumen. Polymer Testing, 27(8), 1005-1012.

Fang, C., Yu, R., Zhang, Y., Hu, J., Zhang, M., \& Mi, X. (2012). Combined modification of asphalt with polyethylene packaging waste and organophilic montmorillonite. Polymer Testing, 31(2), 276-281.

Fang, C., Yu, R., Li, Y., Zhang, M., Hu, J., \& Zhang, M. (2013). Preparation and characterization of an asphalt-modifying agent with waste packaging polyethylene and organic montmorillonite. Polymer Testing, 32(5), 953-960.

Fang, C., Li, T., Zhang, Z., \& Jing, D. (2008). Modification of asphalt by packaging wastepolyethylene. Polymer Composites, 29(5), 500-505.

Fang, C., Zhang, Y., Yu, Q., Zhou, X., Guo, D., Yu, R., \& Zhang, M. (2013). Preparation, characterization and hot storage stability of asphalt modified by waste polyethylene packaging. Journal of Materials Science \& Technology, 29(5), 434-438.

García-Morales, M., Partal, P., Navarro, F. J., Martínez-Boza, F. J., \& Gallegos, C. (2007). Processing, rheology, and storage stability of recycled EVA/LDPE modified bitumen. Polymer Engineering \& Science, 47(2), 181-191.

Gorkem, C., \& Sengoz, B. (2009). Predicting stripping and moisture induced damage of asphalt concrete prepared with polymer modified bitumen and hydrated lime. Construction and Building Materials, 23(6), 2227-2236.

Ghile, D. B. (2006). Effects of nanoclay modification on rheology of bitumen and on performance of asphalt mixtures. Delft, The Netherlands: Delft University of Technology.

Navarro, F. J., Partal, P., García-Morales, M., Martín-Alfonso, M. J., Martinez-Boza, F., Gallegos, C., ... \& Diogo, A. C. (2009). Bitumen modification with reactive and non-reactive (virgin and recycled) polymers: a comparative analysis. Journal of Industrial and Engineering Chemistry, 15(4), 458-464.

Navarro, F. J., Partal, P., Martínez-Boza, F. J., \& Gallegos, C. (2007). Influence of processing conditions on the rheological behavior of crumb tire rubber-modified bitumen. Journal of applied polymer science, 104(3), 1683-1691.

Moreno-Navarro, F., Sol-Sánchez, M., \& Rubio-Gámez, M. C. (2015). The effect of polymer modified binders on the long-term performance of bituminous mixtures: the influence of temperature. Materials \& Design, 78, 5-11.

Naskar, M., Chaki, T. K., \& Reddy, K. S. (2010). Effect of waste plastic as modifier on thermal stability and degradation kinetics of bitumen/waste plastics blend. Thermochimica Acta, 509(1), 128-134.

Naskar, M. O. U. M. I. T. A., Chaki, T. K., \& Reddy, K. S. (2012). A novel approach to recycle the waste plastics by bitumen modification for paving application. In Advanced Materials Research (Vol. 356, pp. 1763-1768). Trans Tech Publications.

Köfteci, S., Ahmedzade, P., \& Kultayev, B. (2014). Performance evaluation of bitumen modified by various types of waste plastics. Construction and Building Materials, 73, 592-602.

Sengoz, B., Topal, A., \& Isikyakar, G. (2009). Morphology and image analysis of polymer modified bitumens. Construction and Building Materials, 23(5), 1986-1992.

Tayfur, S., Ozen, H., \& Aksoy, A. (2007). Investigation of rutting performance of asphalt mixtures containing polymer modifiers. Construction and Building Materials, 21(2), 328-337.

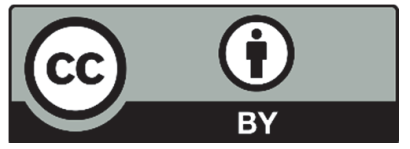

(C) 2018 by the authors; licensee Growing Science, Canada. This is an open access article distributed under the terms and conditions of the Creative Commons Attribution (CC-BY) license (http://creativecommons.org/licenses/by/4.0/). 